\title{
Aedes na Mira 2.0 - Um Jogo Baseado em Realidade Virtual para Prevenção e Combate ao Mosquito Aedes Aegypti
}

\author{
Álan B. R. Miguel $^{1}$, Victor T. Sarinho ${ }^{1}$ \\ ${ }^{1}$ Laboratório de Entretenimento Digital Aplicado - LEnDA \\ Universidade Estadual de Feira de Santana - UEFS \\ Feira de Santana - Bahia - Brasil \\ sosvari21@gmail.com, vsarinho@uefs.br
}

\begin{abstract}
The Brazilian population has been suffering continuously from people infected with Aedes aegypti mosquito diseases, which present alternating outbreaks and difficult-to-combat epidemics, having killed hundreds of people year after year. This work presents the results obtained with the Aedes na Mira 2.0 development, a game that applies virtual reality mechanics and dynamics in a scenario capable of providing a learning context in prevention and combat to the respective mosquito.
\end{abstract}

Resumo. A população brasileira vem sofrendo continuamente com o quadro de pessoas infectadas por doenças provenientes do mosquito Aedes aegypti, as quais apresentam alternâncias de surtos e epidemias de difícil combate, tendo levado a óbito centenas de pessoas ano após ano. Este trabalho apresenta os resultados obtidos com o desenvolvimento do Aedes na Mira 2.0, um jogo que aplica mecânicas e dinâmicas de realidade virtual em um cenário capaz de proporcionar um contexto de aprendizagem na prevenção e no combate ao respectivo mosquito.

\section{Introdução}

Atualmente, o Brasil vem sofrendo com o quadro de pessoas infectadas por doenças provenientes do mosquito Aedes aegypti, tendo levado a óbito cerca de 81 pessoas por febre amarela, 173 pessoas por chikungunya, 141 por dengue e 2 por zika em 2017 [da Silva et al. 2018] [Oliveira 2019]. Trata-se de um mosquito que "é encontrado, principalmente, no meio urbano, colonizado em depósitos de armazenamento de água e pequenas coleções temporárias" [Braga and Valle 2007].

A prevenção ao Aedes aegypti é feita, principalmente, através do combate aos criadouros do mosquito, algo que só é possível por meio da anuência da comunidade às medidas de prevenção informadas e da acepção que elas possuem para as pessoas orientadas [Steffler et al. 2011]. Neste sentido, faz-se necessário desenvolver maneiras criativas e eficazes de disseminação de informações acerca do combate ao mosquito para fins de promover a erradicação do mesmo.

Jogos educativos, também conhecidos por jogos sérios, são tipos de softwares que visam primordialmente objetivos educacionais [Silva and Gomes 2015]. Trata-se de um recurso computacional que pode ser usado como ferramenta para criar novas formas de divulgação, bem como implementar ações de educação, capazes de aumentar o interesse do público no combate ao mosquito [Silva et al. 2008]. 
Neste sentido, este artigo apresenta o estado atual de desenvolvimento do "Aedes na Mira 2.0", um jogo arcade que busca aplicar mecânicas e dinâmicas de jogos de Realidade Virtual (VR) em um cenário que apresenta uma cidade infectada por larvas e mosquitos onde o jogador deve combatê-los de modo a evitar maiores estragos para a sua população.

\section{Metodologia e Resultados}

Diferentes jogos têm sido desenvolvidos no contexto de combate ao mosquito Aedes aegypti. Como exemplo, o Missão Aedes [Araújo et al. 2016] apresenta um jogo estilo plataforma 2D que busca: lembrar quais são os focos do mosquito; entender e analisar o ciclo de vida do mosquito; aplicar os conhecimentos adquiridos referentes aos focos do mosquito; e avaliar o ciclo de desenvolvimento do mosquito (Figura 1(a)). Seguindo o estilo de quiz gráfico, o jogo Aedes Game [Portella et al. 2017] visa informar a população brasileira quanto a sua responsabilidade social diante do combate ao Aedes aegypti, apresentando um conjunto de perguntas e respostas que buscam informar o jogador a partir do feedback quanto às respostas dadas (Figura 1(b)). Para finalizar, o jogo Aedes na Mira [Moura and Sarinho 2017] usa VR para propiciar ao jogador uma imersão no quintal de uma casa repleta de focos de dengue, na qual ele deve eliminar as larvas de mosquitos contidas nos mesmos.

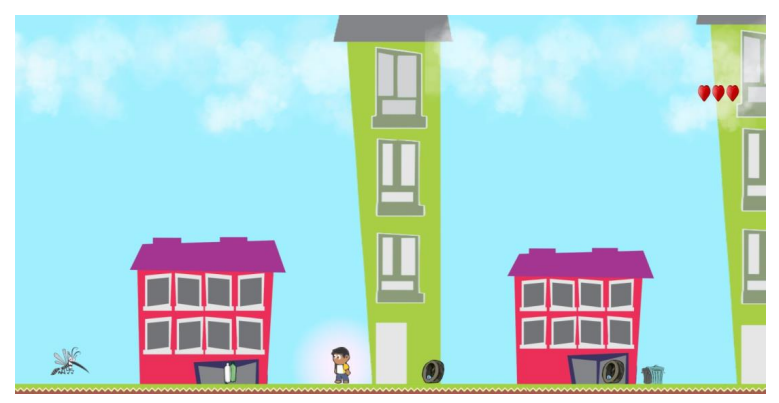

(a) Missão Aedes

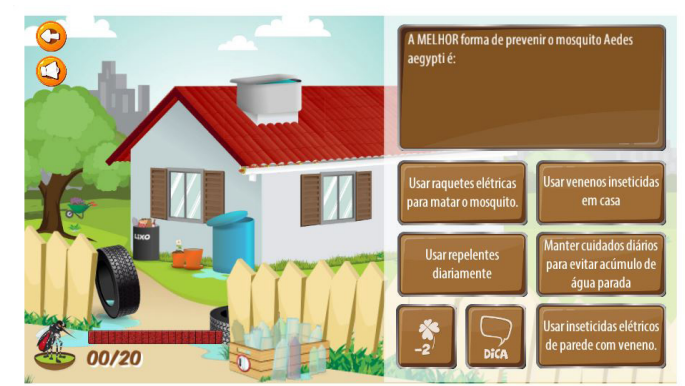

(b) Aedes Game

Figura 1. Jogos digitais voltados para o combate ao Aedes aegypti.

Com relação ao jogo Aedes na Mira 2.0 (Figura 2(a)), trata-se de um jogo estilo First-Person Shooter (FPS) controlado por manetes e óculos VR que apresenta uma cidade infectada por larvas e mosquitos onde o jogador deve combatê-los de modo a evitar maiores estragos (Figura 2(b)).

O jogador inicia a partida em sua residência (Figura 3(a)), na qual deve eliminar os mosquitos e os focos de larvas contidas na mesma. Em seguida ele avança pelo bairro (Figura 3(b)), evitando ataques de mosquitos e eliminando os diversos focos com larvas nas proximidades. Por fim, o personagem deve eliminar os últimos focos do mosquito que se encontram no parque da cidade (Figura 2), destruindo assim a ameaça da cidade e vencendo o jogo.

Os focos ativos são os que possuem larva, já os não ativos são os que apresentam apenas a água parada. O número de focos de larvas simultaneamente ativos é fixo para cada fase do jogo, e, na medida em que eles forem sendo destruídos, o jogo vai escolher de forma aleatória um foco não ativo disponível para ser reativado novamente. 


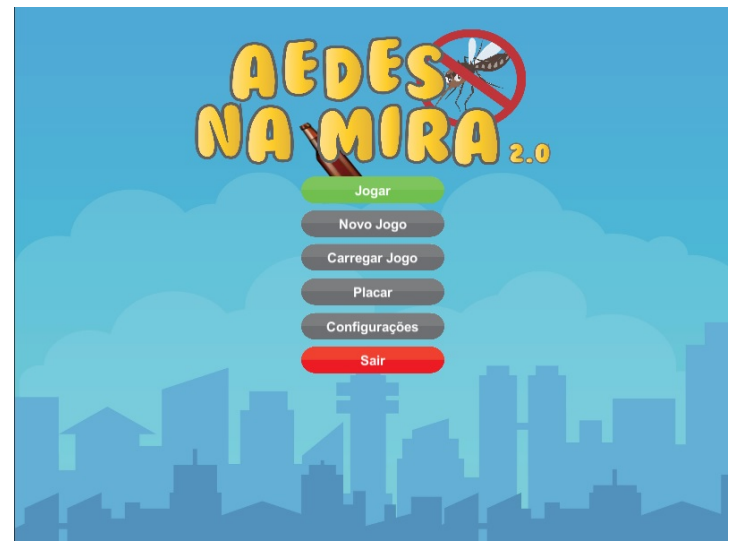

(a) Menu inicial

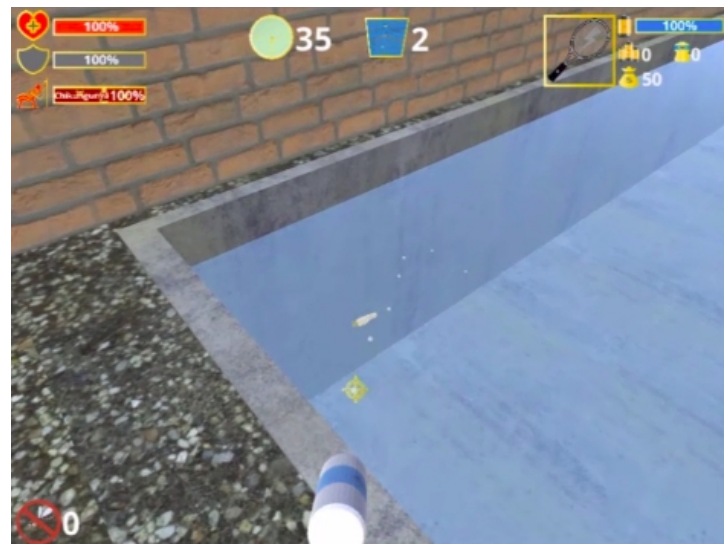

(b) Tela de jogo

Figura 2. Tela inicial e gameplay do Aedes na Mira 2.0.

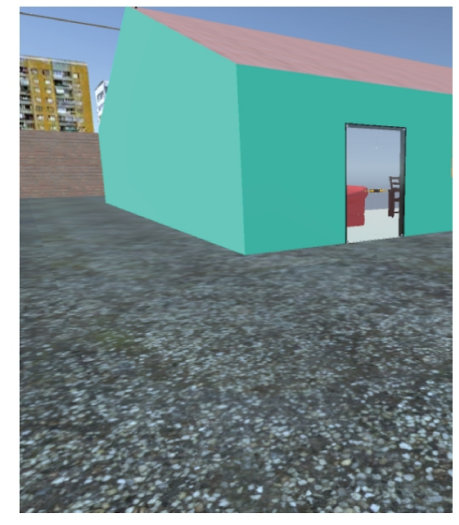

(a) Residência

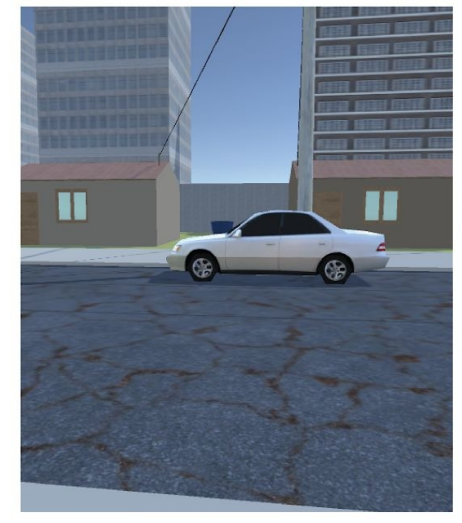

(b) Bairro

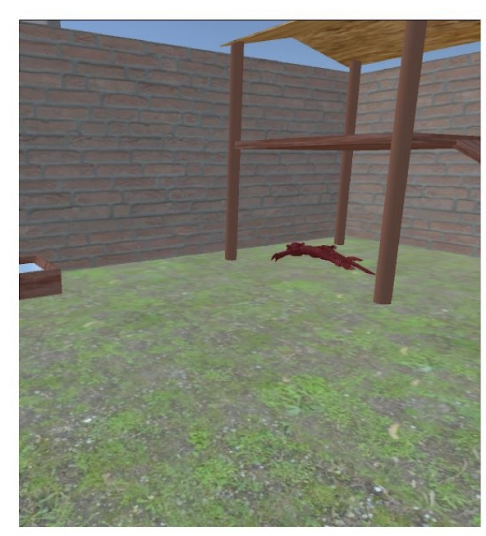

(c) Parque

Figura 3. Cenários de fases do jogo Aedes na Mira 2.0.

Elementos de storytelling também são aplicados ao jogo, a exemplo da televisão informando sobre a epidemia do mosquito e jornais informando sobre macacos mortos no parque da cidade. Tratam-se de recursos que contextualizam as ações do jogador, bem como garantem a imersão e continuidade do mesmo durante uma partida.

Com relação aos inimigos no jogo, o primeiro seria o foco de mosquito com larvas (Figura 4(a)) e o segundo seria o mosquito propriamente dito (Figura 4(b)). Cada tipo de mosquito se divide em quatro categorias, que são os não infectados, os infectados com dengue, os infectados com zika e por fim os infectados com chikungunya. Mosquitos emitem um som crescente a medida em que se aproximam do jogador, e, sempre que o jogador destruir um mosquito durante a partida, um novo mosquito nascerá a partir de um dos focos ativos de larvas disponível nas proximidades.

Para o sistema de recompensa do jogo, tem-se que a destruição de inimigos aumenta os créditos e os pontos de vida do jogador, permitindo estender o tempo de vida do mesmo bem como realizar a compra de novas armas durante a partida (Tabela 1). Duas armas foram inicialmente projetadas para o jogo, sendo a primeira, uma arma que dispara gotas de água sanitária e serve para matar larvas, e a segunda, uma raquete elétrica que 


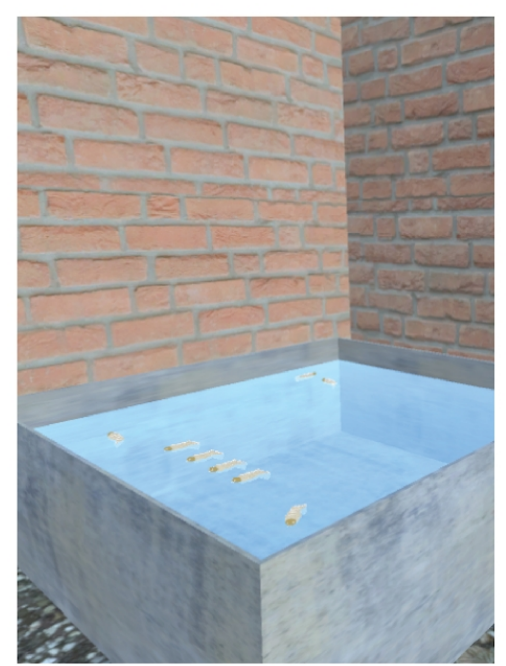

(a) Larvas

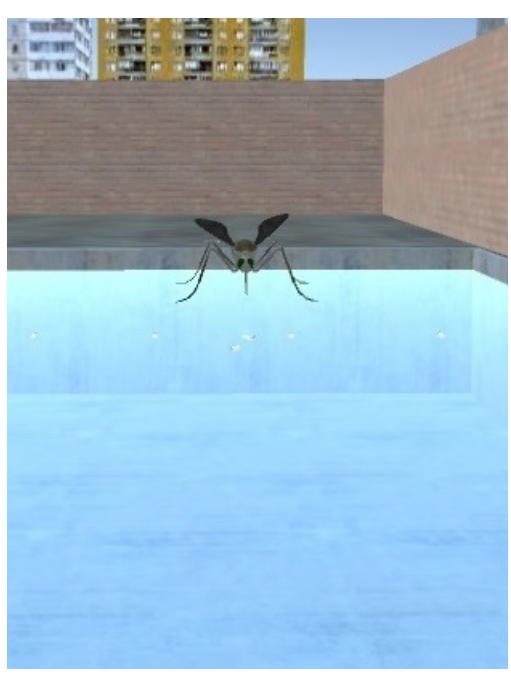

(b) Mosquito

Figura 4. Exemplos de inimigos no jogo Aedes na Mira 2.0.

pode ser usada para matar mosquitos (Tabela 2). Ambas as armas irão usar um sistema de cores para indicar variantes das mesmas com mais poder de destruição de larvas e mosquitos (Tabela 2). Bombas de água sanitária, para matar todas as larvas no seu raio de ação, inseticidas, para matar todos os mosquitos no raio de ação, e repelentes, para evitar a aproximação de mosquitos por um determinado tempo, também serão acrescentados como armas especiais a serem obtidas durante o jogo. Vale ressaltar que o jogador começa o jogo com apenas uma raquete elétrica simples, de cor cinza e de munição infinita, mas que oferece pouco dano ao mosquito.

Tabela 1. Inimigos, pontuações e pontos de vida gerados após a sua destruição.

\begin{tabular}{|c|c|c|}
\hline Inimigo & Créditos & Pontos de Vida \\
\hline Mosquito não infectado & 2.5 & 100 \\
\hline Mosquito com dengue & 15 & 100 \\
\hline Mosquito com chikungunya & 5 & 100 \\
\hline Mosquito com Zika & 10 & 100 \\
\hline Foco de mosquito & 50 & - \\
\hline Larva & - & 100 \\
\hline
\end{tabular}

Para fins de ilustração, a Figura 5 apresenta o Head-Up Display (HUD) do jogo contendo elementos do sistema de pontuação, do sistema de recompensa, armas disponíveis para uso, dentre outros disponíveis conforme listagem abaixo:

1. Mira que permite ver quanto de vida tem o inimigo;

2. Escudo que garante proteção ao jogador e é carregado por repelente;

3. Barra de enfermidade que pode ser ativada por qualquer uma das doenças causadas pelo mosquito;

4. Relógio indicador de tempo corrido do jogo; 
Tabela 2. Armas, valores para compra de acordo com a dificuldade e dano ao inimigo.

\begin{tabular}{|c|c|c|c|c|}
\hline Arma & Fácil & Normal & Díficil & Dano \\
\hline Raquete Cinza & - & - & - & 10 \\
\hline Raquete Azul & 30 & 150 & 300 & 20 \\
\hline Raquete Vermelha & 80 & 400 & 800 & 50 \\
\hline Raquete Dourada & 200 & 1000 & 2000 & 100 \\
\hline Água S. Azul 1 Litro & 50 & 250 & 500 & 20 \\
\hline Água S. Vermelha 1 Litro & 100 & 500 & 1000 & 50 \\
\hline Água S. Dourada 1 Litro & 250 & 1250 & 2500 & 100 \\
\hline Água S. Dourada 1 Litro & 250 & 1250 & 2500 & 100 \\
\hline
\end{tabular}

5. Contador de tempo para o surgimento de um novo foco de mosquito;

6. Indicador de focos de água parada com mosquitos;

7. Contador de focos de mosquitos ativos no momento;

8. Arma em uso pelo jogador;

9. Créditos recebido no jogo disponível para uso;

10. Quantidade de pilha disponível;

11. Quantidade de repelente disponível;

12. Indicador de carga corrente de pilha em uso;

13. Indicador de quantos mosquitos já foram mortos;

14. Indicador de vida do inimigo corrente; e

15. Indicador de vida do jogador.

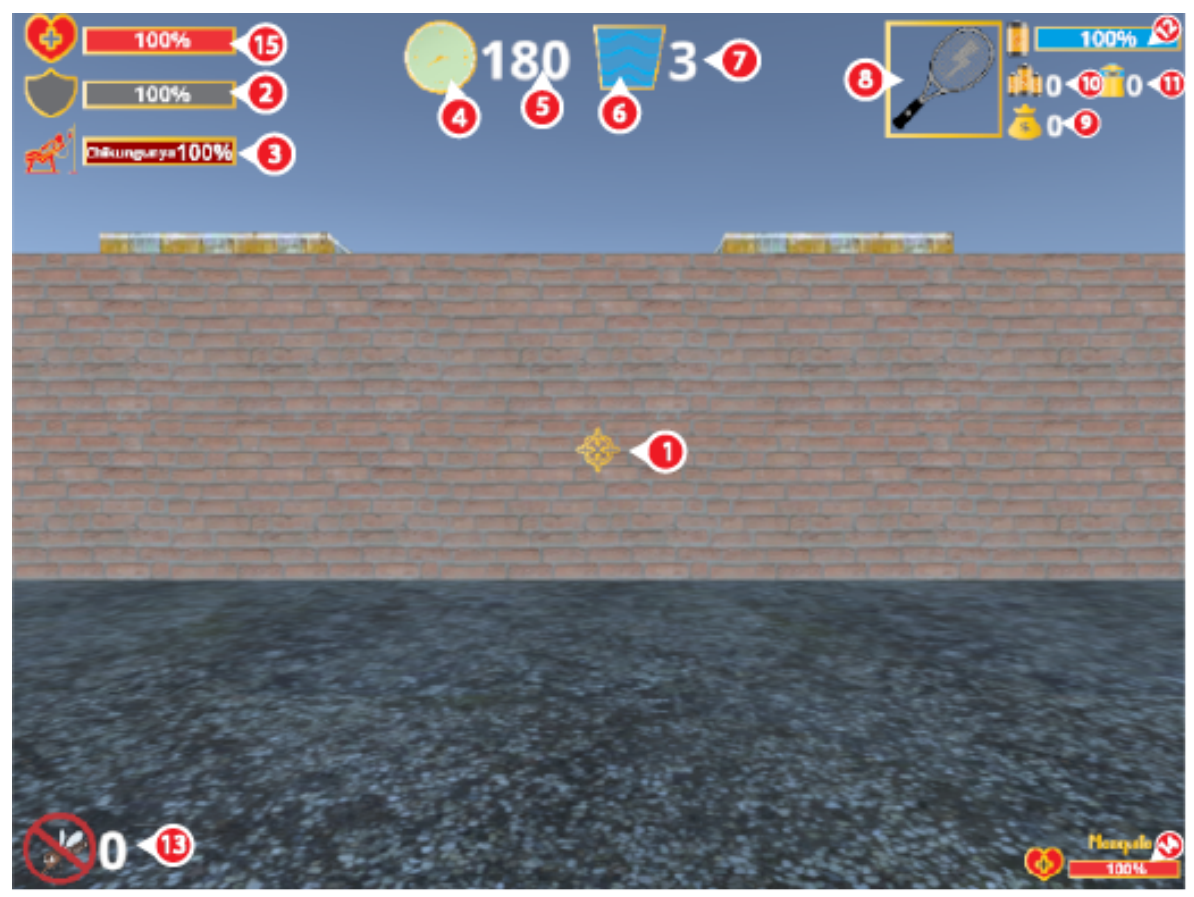

Figura 5. HUD inicialmente proposto para o jogo Aedes na Mira 2.0. 


\section{Conclusões e Trabalhos Futuros}

Este artigo apresentou o estado atual de desenvolvimento do Aedes na Mira 2.0, um jogo que objetiva aplicar dinâmicas de FPS em realidade virtual na prevenção e no combate ao mosquito Aedes aegypti. Trata-se de uma aplicação lúdica voltada para o público em geral, de modo que se possa vivenciar estratégias de prevenção e combate ao mosquito representadas pelos elementos inseridos no jogo.

Com relação ao desenvolvimento do jogo, este ainda se encontra na fase inicial de produção, sendo necessário: aplicar as abordagens de renderização para óculos VR; colocar os mosquitos para atacarem o personagem; criar o sistema de compra de armas; melhoras as informações disponibilizadas no HUD; otimizar os menus e os cenários das fases; criar um personagem para que os jogadores possam ver o mesmo no modo de visão em terceira pessoa; dentre outras pendências existentes.

Como trabalhos futuros, pretende-se estender o sistema gráfico do jogo, permitindo que o mesmo rode em diferentes plataformas mobile existentes. Integração com redes sociais diversas, ampliando o sistema de recompensa do jogo para o ambiente externo e cultural em que seus jogadores vivem, bem como a realização de testes de avaliação da usabilidade do jogo produzido, também serão realizados em um futuro próximo.

\section{Referências}

Araújo, D., Rodrigues, A., Lacerda, P., Dionísio, M., and Santos, H. (2016). Processo de desenvolvimento do jogo sério missão aedes: relações entre objetivos pedagógicos, ludicidade e implicações de design. In Brazilian Symposium on Computers in Education - SBIE), volume 27, page 597.

Braga, I. A. and Valle, D. (2007). Aedes aegypti: histórico do controle no brasil. Epidemiologia e serviços de saúde, 16(2):113-118.

da Silva, C. P., de Macedo Quinino, L. R., do Rego, C. P., and Freire-Silva, J. (2018). Um estudo bibliográfico acerca dos surtos de febre amarela no brasil. Revista Brasileira de Meio Ambiente, 2(1).

Moura, J. V. C. and Sarinho, V. T. (2017). Aedes na mira - aplicando realidade virtual no combate a focos de mosquitos. In Workshop de eXperimentos Bahia-Alagoas-Sergipe (XBASE 2017). ERBASE.

Oliveira, M. (2019). Chikungunya foi a doença transmitida pelo aedes que mais matou em 2017 no país. https://g1.globo.com/bemestar/noticia/chikungunya-foi-a-doencatransmitida-pelo-aedes-que-mais-matou-em-2017-no-pais.ghtml.

Portella, F. F., Tubelo, R. A., Zanatta, E. J., and Pinto, M. E. B. (2017). Experiência da una-sus/ufcspa no desenvolvimento de jogos educacionais.

Silva, A. C. B. d. and Gomes, A. S. (2015). Conheça e utilize software educativo: avaliação e planejamento para a educação básica. Recife: Pipa Comunicação.

Silva, T. D., Cardoso, F. S., Rodrigues, C. R., Liberto, M. I., Currié, M., Vannier, M. A., and Castro, H. C. (2008). Jogos virtuais no ensino: usando a dengue como modelo. Revista Brasileira de Ensino de Ciência e Tecnologia, 1(2).

Steffler, L. M., Marteis, L. S., and dos Santos, R. L. C. (2011). Fontes de informação sobre dengue e adoção de atitudes preventivas. Scientia Plena, 7(6). 